\title{
Switch to SGLT2 Inhibitors and Improved Endothelial Function in Diabetic Patients with Chronic Heart Failure
}

\author{
Michele Correale ${ }^{1} \cdot$ Pietro Mazzeo $^{2} \cdot$ Adriana Mallardi $^{2} \cdot$ Alessandra Leopizzi $^{2} \cdot$ Lucia Tricarico $^{2} \cdot$ Martino Fortunato $^{2}$. \\ Michele Magnesa ${ }^{2} \cdot$ Salvatore Tucci $^{2} \cdot$ Pasquale Maiellaro $^{2} \cdot$ Giuseppe Pastore $^{2} \cdot$ Olga Lamacchia $^{2}$. \\ Massimo lacoviello ${ }^{2} \cdot$ Matteo Di Biase $^{2} \cdot$ Natale Daniele Brunetti ${ }^{2}$
}

Accepted: 31 August 2021 / Published online: 14 September 2021

(c) The Author(s) 2021

\begin{abstract}
Purpose The use of sodium-glucose-cotransporter-type-2 inhibitors (SGLT2i) was associated in previous studies with an improved vascular function in non-human experimental models. We therefore sought to evaluate possible changes in endothelial function assessed by flow-mediated dilation (FMD) in patients with chronic heart failure (CHF) and type-2 diabetes mellitus (T2DM), switching from other oral hypoglycemic agents to SGLT2i in an observational study.

Methods Twenty-two consecutive outpatients with CHF and T2DM were enrolled after switching to SGLT2i therapy, and compared with 23 consecutive controls from the same registry comparable for principal clinical characteristics. In all patients, endothelial function was assessed by FMD at baseline and after 3 months of follow-up.

Results Three months of therapy with SGLT2i were associated with a statistically significant improvement in endothelial function $(19.0 \pm 5.7 \%$ vs $8.5 \pm 4.1 \%, p<0.0001)$; baseline levels of FMD were comparable between groups (p n.s.). Therapy with SGLT2i was significantly associated to improved FMD levels even at multivariable stepwise regression analysis $(p<0.001)$.

Conclusions Switch to SGLT2i in patients with CHF and T2DM was associated in an observational non-randomized study with an improved endothelial function.
\end{abstract}

Keywords Chronic heart failure · Type 2 diabetes mellitus · Sodium-glucose-cotransporter-2 inhibitors · SGLT2 . Endothelial dysfunction $\cdot$ Gliflozins $\cdot$ Flow-mediated dilation

Natale Daniele Brunetti

natale.brunetti@unifg.it

Michele Correale

opsfco@tin.it

Pietro Mazzeo

pietromazzeo91@tiscali.it

Adriana Mallardi

adriana.mallardi@yahoo.it

Alessandra Leopizzi

alessandraleopizzi91@gmail.com

Lucia Tricarico

lucia.tricarico.lt@gmail.com

Martino Fortunato

dottor.martinofortunato@gmail.com

Michele Magnesa

michele.magnesa17@gmail.com

\author{
Salvatore Tucci \\ salvatoretucci0058@gmail.com \\ Pasquale Maiellaro \\ maiellaropasquale87@gmail.com \\ Giuseppe Pastore \\ giuseppe_pastore.546389@unifg.it \\ Olga Lamacchia \\ olga.lamacchia@unifg.it \\ Massimo Iacoviello \\ massimo.iacoviello@gmail.com \\ Ospedali Riuniti University Hospital, Foggia, Italy \\ 2 Department of Medical and Surgical Sciences, University \\ of Foggia, Foggia, Italy
}




\section{Background}

In the last decades, the prevalence of diabetes mellitus (DM) worldwide has almost doubled, from $4.7 \%$ in 1984 to $9.3 \%$ in 2019 [1]. Type-2 DM (T2DM) is a major risk factor for several cardiovascular (CV) conditions, including heart failure (HF) and endothelial dysfunction (ED).

Sodium-glucose-cotransporter-type- 2 inhibitors (SGLT2i) represent a new class of anti-hyperglycemic agents for T2DM, which act as insulin independent to selectively inhibit renal glucose reabsorption, thereby increasing urinary glucose excretion. The EMPA-REG OUTCOME trial [2] was the first to demonstrate significant cardioprotective benefits in HF patients with empagliflozin, a SGLT2i. Its impressive 35\% reduction in HF hospitalizations supported a possible role for SGLT2i among drugs for HF therapy, either with or without diabetes. This hypothesis was further confirmed in two other large randomized placebo-controlled trials, the CANVAS [3] with canagliflozin and the DECLARETIMI 58 [4] with dapagliflozin, and real-life data from the CVD-Real Study [5].

The use of SGLT2i was associated in previous studies with an improved vascular function in non-human experimental models [6-8]; this improvement may represent an important mechanism underlying the cardiovascular benefits of SGLT2i treatment. However, less is known on possible effect of gliflozins on endothelial function in humans. We therefore sought to evaluate possible changes in endothelial function assessed by flow-mediated dilation (FMD) in patients with CHF and T2DM switching from other oral hypoglycemic agents to SGLT2i in an observational study.

\section{Methods}

Out of 250 patients enrolled in the Daunia Heart Failure Registry as reported elsewhere [9-11], 85 consecutive outpatients with CHF and T2DM were screened; 45 were enrolled and followed up between May 2019 and September 2020; 22 of them after switching to SGLT2i according to independent judgment of their referent endocrinologist in our University Hospital and recommendations of the position statement from Heart Failure Association of the European Society of Cardiology [12], the consensus report by the American Diabetes Association and the European Association for the Study of Diabetes [13] (in patients with HF receiving dual or multiple glucoselowering medications, not including SGLT2i, a switch to an SGLT2i has been recommended), and 2019 ESC Guidelines on diabetes [14] (first-line treatment of DM in
HF should include metformin and gliflozins). Exclusion criteria included $\mathrm{HbA} 1 \mathrm{c}<6.5 \%$, eGFR $<60 \mathrm{~mL} / \mathrm{min} / 1.73$ $\mathrm{m}^{2}$, age $<18$ years, previous amputation surgery, recurrent urinary tract infections, LVEF $>50 \%$, and changes in the antidiabetic treatment during the study. Patients with other diabetes-related comorbidities (retinopathy, nephropathy ...) were excluded.

Twenty-two consecutive patients were therefore treated with SGLT2i and compared with 23 consecutive controls from the same registry comparable for principal clinical characteristics who did not switch to therapy with gliflozins.

In all patients, endothelial function was assessed by FMD at baseline and after 3 months of follow-up. Medical history, heart rate, systolic blood pressure, body mass index, NYHA functional class, and medications were recorded. All patients underwent blood analysis and ECG in an ambulatory setting, under resting conditions at baseline and after 3 months of therapy with SGLT2i. Glycated hemoglobin (HbA1c), high-sensitivity C-reactive protein (CRP), and NTproBNP levels were assayed. Circulating levels of CRP were assessed on venous blood samples drawn from the antecubital vein, using an ethylenediamine-tetra-acetic acid (EDTA) test tube; high-sensitivity CRP was quantified by a highly sensitive immunoassay technique.

\section{Endothelial Function}

FMD of the brachial artery was assessed under standardized condition, according to the "Brachial Artery Reactivity Task Force's guidelines" [15]. The patients were fasting and avoided exercise for at least $8 \mathrm{~h}$ before the exam as well as nicotine, exciting substances like chocolate or coffee/ tea for at least $4 \mathrm{~h}$ and all medications affecting vascular tone or cardiac output for four half-lives. A preliminary scan explored the anatomy and identified landmarks, paying attention to the presence of calcifications, arterial tortuosity, and atherosclerotic plaque. The brachial artery was evaluated in a long axis projection between 5 and $10 \mathrm{~cm}$ above the elbow. All patients were evaluated by the same operator to minimize the bias. A high-resolution US device Philips EPIQ 7C ultrasound system with vascular software, a 7.5-12-MHz linear array transducer, and an ECG-gated image capture system for calculating the brachial artery diameter in real time by analyzing B mode US images were used. The arm was positioned comfortably thanks to a stereotactic probe-holding device. With the subject in supine position for at least $10 \mathrm{~min}$, a sphygmomanometer cuff was placed in the distal site to the artery, in cases of a humeral artery on the forearm. After $1 \mathrm{~min}$ of flow image baseline acquisition, the artery was occluded by inflating the cuff to a suprasystolic pressure for $5 \mathrm{~min}$ (typically at least $50 \mathrm{mmHg}$ above systolic pressure). 
Reactive hyperemia was evaluated as the ratio of the change in diameter (maximal dilatation after deflation baseline) divided by the baseline value, which corresponds to the maximum FMD recovery value. FMD was analyzed as the percentage increase in brachial artery diameter after the application of a pressure stimulus, as reported elsewhere [16].

\section{Statistical Analysis}

Continuous variables were expressed as mean \pm standard deviation and compared with Student's $t$-test, and categorical variables as percentages and compared with $\chi^{2}$ test. Mean values were compared with Student's $t$-test for variables with a normal distribution or with the Mann-Whitney non-parametric $U$ test for variables with a non-normal distribution. Repeated measures were compared with Student's $t$-test for paired samples, and Wilcoxon's test and ANOVA for repeated measured as required. Linear correlations were determined by measuring the Pearson correlation coefficient. Multivariable stepwise regression analysis was used to assess possible bias of confounders. A $p<0.05$ was considered statistically significant.

\section{Sample Sizing}

On the base of prior data on FMD changes [17], an expected FMD change of at least $5 \%$ over time, an $80 \%$ power, and $\alpha$ of 0.05 , groups of at least 11 subjects were required for the analysis.

\section{Results}

Population characteristics are given in Table 1; $81 \%$ of patients were treated with beta-blockers, and $86 \%$ with ACE-inhibitors/angiotensin receptor blockers/angiotensin neprilysin inhibitors.

Twenty-two patients were treated with SGLT2 inhibitors and compared with twenty-three controls comparable for principal clinical characteristics. Of 22 patients treated with SGLT2i, 64\% (14) received empagliflozin, 18\% (4) dapagliflozin, and 18\% (4) canagliflozin; 3 were also treated with both insulin and oral antidiabetics (14\%), 8 with insulin (36\%), and 9 with OAD (41\%). Of 23 patients not receiving SGLT2i, 2 were treated with both insulin and OAD (8.7\%), 5 with insulin (21.7\%), and 16 with OAD (69.6\%). Data on OAD are given in Supplementary Fig. 1 (S1).

After a 3-month follow-up, the patients who started therapy with SGLT2i showed a statistically significant improvement in endothelial function $(19.0 \pm 5.7 \%$ vs $8.5 \pm 4.1 \%$, $p<0.0001$, ANOVA $p$ vs controls $<0.001$, Fig. 1 ); baseline levels of FMD were comparable between groups (p n.s.).

Treatment with SGLT2i was also associated with statistically significant reductions in glycated hemoglobin levels $(7.7 \pm 1.0 \%$ vs $8.2 \pm 1.2 \%, p<0.01)$ and non-significant reductions in CRP $(2.0 \pm 2.2$ vs $3.0 \pm 3.6 \mathrm{mg} / \mathrm{dl}$, p n.s. $)$ and NTproBNP levels $(581.6 \pm 564.5$ vs $1609.3 \pm 2543.3$, $p$ 0.09).

Changes in FMD values were not proportional to changes in NTproBNP, CRP, and glycated hemoglobin
Table 1 Population's characteristics

\begin{tabular}{|c|c|c|c|c|c|}
\hline \multirow[t]{2}{*}{ Variables } & \multicolumn{2}{|c|}{ SGLT2 inhibitors } & \multicolumn{2}{|c|}{ Other antidiabetic drugs } & \multirow[t]{2}{*}{$p$-value } \\
\hline & Mean \pm SD & $\%$ & Mean \pm SD & $\%$ & \\
\hline Age (years) & $66 \pm 9$ & & $71 \pm 9$ & & 0.0693 \\
\hline Male $(\%)$ & & $91 \%$ & & $70 \%$ & 0.0765 \\
\hline COPD (\%) & & $14 \%$ & & $26 \%$ & 0.3074 \\
\hline Hypertension & & $77 \%$ & & $74 \%$ & 0.7988 \\
\hline Obesity (BMI > 30) & & $36 \%$ & & $35 \%$ & 0.9143 \\
\hline NYHA class & $2.1 \pm 0.5$ & & $2.2 \pm 0.7$ & & 0.1358 \\
\hline Years of diabetes & $9 \pm 7$ & & $9 \pm 4$ & & 0.7439 \\
\hline Systolic blood pressure (mmHg) & $118 \pm 28$ & & $112 \pm 16$ & & 0.3756 \\
\hline Creatinine (mg/dl) & $1.0 \pm 0.2$ & & $1.1 \pm 0.2$ & & 0.2730 \\
\hline NT-pro-BNP (pg/ml) & $1595 \pm 2411$ & & $638 \pm 607$ & & 0.0730 \\
\hline HbA1c (\%) & $8 \pm 1$ & & $8 \pm 1$ & & 0.9879 \\
\hline Left ventricular ejection fraction (\%) & $41 \pm 7$ & & $40 \pm 7$ & & 0.8254 \\
\hline ACEi/ARB/sacubitril-valsartan (\%) & & $86 \%$ & & $87 \%$ & 0.9073 \\
\hline Beta-blockers (\%) & & $91 \%$ & & $81 \%$ & 0.3290 \\
\hline Mineralcorticoid receptor antagonist (\%) & & $62 \%$ & & $35 \%$ & 0.0750 \\
\hline Loop diuretics (\%) & & $86 \%$ & & $83 \%$ & 0.7846 \\
\hline Ivabradine $(\%)$ & & $14 \%$ & & $4 \%$ & 0.2624 \\
\hline Digoxin $(\%)$ & & $10 \%$ & & $4 \%$ & 0.5076 \\
\hline
\end{tabular}




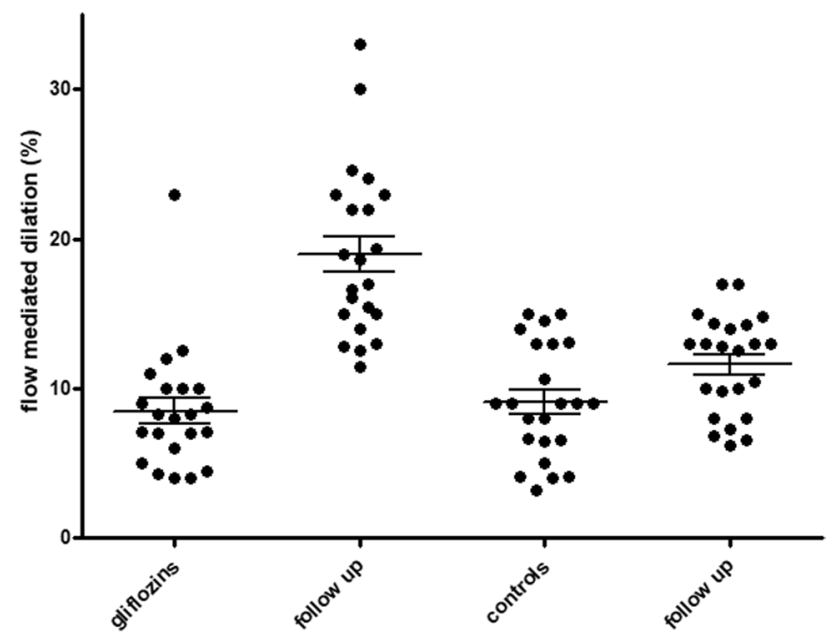

Fig. 1 Stress-rest radial artery diameter difference (\%) derived by flow-mediated dilation between patients in therapy with SGLT2 inhibitors and patients with other antidiabetic drugs

levels at univariate analysis, but were related to baseline FMD values ( $r=-0.62, p<0.05$, Fig. 2$)$. Changes in FMD values were not proportional to baseline glycated hemoglobin levels.

Therapy with SGLT2i was significantly correlated to improved FMD levels even at multivariable stepwise regression analysis in a model including age, gender, baseline FMD levels, LVEF, EDV, NTproBNP, CRP, HbA1c values, changes in percent of NTproBNP, CRP, and HbA1c $(p<0.001)$ (Table 2).

\section{Discussion}

To the best of our knowledge, this one the first studies showing an improved endothelial function after therapy with gliflozins in patients with CHF and T2DM. The improvement in endothelial function does not seem to likewise correlate

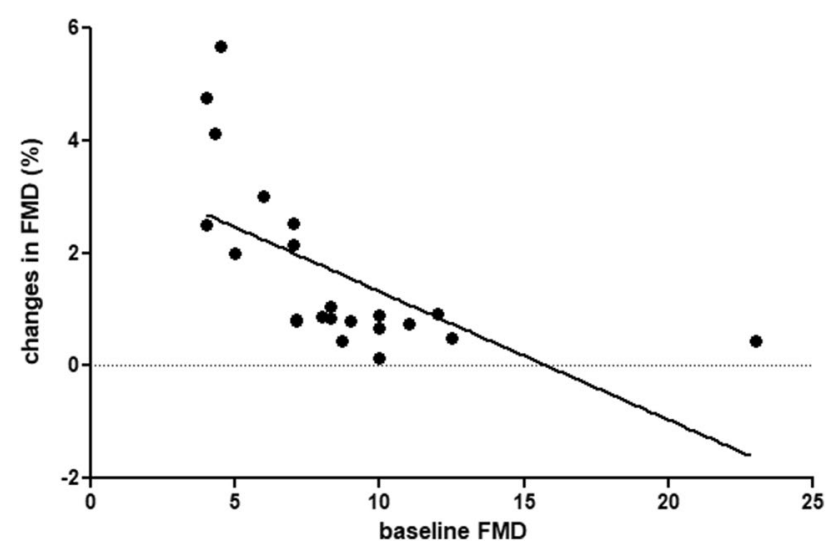

Fig. 2 Correlation between baseline FMD values and changes in FMD (in percent, $p<0.05$ )
Table 2 Predictors of improved flow-mediated dilation at multivariable stepwise regression analysis

\begin{tabular}{llll}
\hline & $b$ & Std. Err & $p$-value \\
\hline Baseline flow-mediated dilation levels & -0.15 & 0.04 & 0.0034 \\
Use of SGLT2 inhibitors & 1.33 & 0.34 & 0.0009 \\
Change in glycated hemoglobin levels & -7.30 & 2.70 & 0.0140 \\
Change in C-reactive protein levels & 0.76 & 0.34 & 0.0373 \\
Baseline C-reactive protein levels & -0.16 & 0.07 & 0.0447 \\
\hline
\end{tabular}

with changes in NTproBNP, CRP, and glycated hemoglobin levels, suggesting an independent effect of gliflozins on endothelial function beyond glucose-lowering effects.

Impaired endothelial function plays the pivotal role in the pathophysiology of atherogenesis and is usually accompanied by increased oxidative stress and inflammatory responses. ED may also play an important role in the pathogenesis of HF. The interplay between CHF, inflammation, and ED is extremely complex and multifaceted [18]. CHF is characterized by an inflammatory activation [19] and ED, partly secondary to systemic inflammation. Oxidative stress has been shown to play an important role in the pathophysiology of cardiac remodeling and HF [20].

Recent animal studies have demonstrated that treatment with SGLT2i can reduce oxidative stress and the inflammation processes. The inhibition of SGLT2 by phlorizin prevents the hyperglycemia and oxidative stress in kidney of diabetic rats [21]. Empagliflozin significantly ameliorated in mice the impairment of vascular dilating function, with attenuation of oxidative stress in cardiovascular tissue [22]. In high-fat diet and streptozotocin-nicotinamide-induced type 2 diabetic mice which exhibit impaired insulin secretion, insulin resistance, hyperlipidemia, hepatic steatosis, and obesity, ipragliflozin reduced plasma and liver levels of oxidative stress biomarkers and inflammatory markers (interleukin 6, tumor necrosis factor $\alpha$, monocyte chemotactic protein-1, and CRP) [23].

The use of SGLT2 $i$ is associated in previous studies with an improved vascular function in animal models. Empagliflozin improved diabetes-induced vascular dysfunction in the streptozotocin diabetes rat model by interfering with oxidative stress and glucotoxicity [24]. Glycemic control with ipragliflozin ameliorated endothelial dysfunction in streptozotocin-induced diabetic mouse [25].

Our results are in line with several previous works in experimental models. Juni et al. demonstrated that therapy with empagliflozin may provide beneficial effects on cardiac microvascular endothelial cells by reducing mithocondrial ROS production and cytoplasmatic ROS accumulation, which led to restoration of endothelial NO bioavailability [26]. Shigiyama et al. [27] reported that 
16 weeks of treatment with dapagliflozin, in patients with a short duration of T2DM and no history of atherosclerotic CVD, improved endothelial function measured by flow-mediated vasodilation, compared with that associated with an increased dose of metformin. Solini et al. [28] also reported that 2 days of treatment with dapagliflozin acutely improved endothelial function in T2DM patients at low risk of $\mathrm{CV}$ events.

However, in the EMBLEM trial [29], a multicenter, placebo-controlled, double-blind, randomized trial designed to evaluate the effect of empagliflozin on endothelial function as assessed by reactive hyperemia-peripheral arterial tonometry (RH-PAT) in patients with T2DM and established CVD, 24 weeks of treatment did not affect endothelial function compared with placebo. The study did not include a detailed evaluation of responders and non-responders to empagliflozin therapy. In a secondary and exploratory analysis of the study by Tanaka et al. [30] empagliflozin treatment for 24 weeks had fewer direct effects on vascular function, at least in patients with T2DM and established CVD. It is quite likely that population bias might have influenced the results of this trial; several T2DM patients had a history of established CVD, including or HF or coronary artery disease or stroke or peripheral artery disease or the presence of coronary artery stenosis $(\geq 50 \%)$.

Recently, rationale and design of an investigator-initiated, multicenter, prospective open-label, randomized trial to evaluate the effect of ipragliflozin on endothelial dysfunction in T2DM and chronic kidney disease (the PROCEED trial) [31] and of a prospective, single-center, investigator-blinded, open-label, randomized clinical trial (empagliflozin $25 \mathrm{mg} /$ day alone or empagliflozin $25 \mathrm{mg}$ /day plus evolocumab $140 \mathrm{mg}$ every 2 weeks in addition to optimal medical care) to evaluate the add-on effect of PCSK9i on endothelial function of T2DM patients under regular use of empagliflozin [32] have been published.

Results from ADDENDA-BHS2 study (a prospective, single-center, active-controlled, open, randomized trial, where ninety-eight participants were randomized to either dapagliflozin $10 \mathrm{mg} /$ day or glibenclamide $5 \mathrm{mg}$ /day on top of metformin) demonstrated that dapagliflozin improved micro- and macrovascular endothelial function compared to glibenclamide (rest FMD changed by $+3.3(8.2) \%$ and $-1.2(7.5) \%$ for the dapagliflozin and glibenclamide arms, respectively $(p=0.0001)$ ), regardless of glycemic control in patients with T2DM and subclinical carotid atherosclerotic disease [33]. Several hypotheses have been proposed to explain cardioprotective effects of SGLT2 inhibitors $[34,35]$. SGLT2 inhibitors are hypothesized to increase natriuresis, with unique properties leading to a reduction in preload and myocardial stretch (the diuretic hypothesis); exert many anti-inflammatory effects (the anti-inflammatory effects hypothesis); act through the angiotensin II type II receptors leading to vasodilation (the RAAS hypothesis); and exhibit also inhibitory action possibly resulting in an attenuation of oxidative stress (the SGLT1 inhibition hypothesis) [36]. Irace et al. demonstrated that, through osmotic diuresis, empagliflozin may increases blood viscosity and, consequently, shear stress, which is the major hemodynamic force acting on the endothelial surface and promoting the synthesis of vasoactive and athero-protective substances [37, 38]. Dapagliflozin induces vasodilation via the activation of $\mathrm{Kv}$ channels and protein kinase $\mathrm{G}$, and is independent of other $\mathrm{K}+$ channels, $\mathrm{Ca} 2+$ channels, intracellular $\mathrm{Ca} 2+$, and the endothelium [39].

Sympatholysis, i.e., reduction in sympathetic nervous system (SNS) activity, could be a potential mechanism for the apparent endothelial benefits of the SGLT2i switch in the patients affected by HF with T2DM. Probably, SGLT2is alleviate the renal stress responsible for sympathetic activation [40]. Despite increasing experimental and clinical data [41] demonstrated a reduction in SNS activity, the mechanisms linking SGLT2 and SNS need of further investigation. However, the failure to increase heart rate despite reductions in blood pressure and plasma volume may suggest a decrease of SNS activity in patients affected by HF with or without T2DM in treatment with gliflozins.

Randomized adequately powered studies are warranted to confirm vasoactive effect of SGLT2i preliminary shown in small observational studies.

\section{Conclusions}

Switch to SGLT2i in patients with CHF and T2DM was associated in an observational non-randomized study with an improved endothelial function.

\section{Limitations}

Main limitation of the study is the small number of patients enrolled and the observational nature of the study; these preliminary results need to be confirmed in properly powered multicentric and randomized studies.

No data are available on plasma levels of nitrite/nitrate and or endothelin, which would be of great interest in order to clarify possible pathways of interaction.

The study is underpowered to consider possible difference between groups of borderline significance (see mineralocorticoids receptor antagonists).

Supplementary Information The online version contains supplementary material available at https://doi.org/10.1007/s10557-021-07254-3. 
Author Contribution MC ideated the study.

$\mathrm{PM}, \mathrm{AM}, \mathrm{AL}$, and LT collected data and wrote the manuscript. MF, MM, ST, PM, GP, OL, and MI revised the manuscript.

$\mathrm{MC}$ and MDB revised the manuscript.

MDB and OL supervised the study.

NDB revised the manuscript, performed statistical analysis, and supervised the study.

Funding Open access funding provided by Università di Foggia within the CRUI-CARE Agreement.

Data Availability Data are available on reasonable request.

\section{Declarations}

Ethics Approval and Consent to Participate This is an observational study waived from ethics approval; all participants gave their consent to participate.

Consent for Publication All authors consent to publication.

Conflict of Interest The authors declare no competing interests. Author note: None of the paper's contents have been previously published.

Open Access This article is licensed under a Creative Commons Attribution 4.0 International License, which permits use, sharing, adaptation, distribution and reproduction in any medium or format, as long as you give appropriate credit to the original author(s) and the source, provide a link to the Creative Commons licence, and indicate if changes were made. The images or other third party material in this article are included in the article's Creative Commons licence, unless indicated otherwise in a credit line to the material. If material is not included in the article's Creative Commons licence and your intended use is not permitted by statutory regulation or exceeds the permitted use, you will need to obtain permission directly from the copyright holder. To view a copy of this licence, visit http://creativecommons.org/licenses/by/4.0/.

\section{References}

1. Saeedi P, Petersohn I, Salpea P, Malanda B, Karuranga S, Unwin N, Colagiuri S, Guariguata L, Motala AA, Ogurtsova K, Shaw JE, Bright D, Williams R; IDF Diabetes Atlas Committee. Global and regional diabetes prevalence estimates for 2019 and projections for 2030 and 2045: results from the International Diabetes Federation Diabetes Atlas, 9th edition. Diabetes Res Clin Pract. 2019;157:107843.

2. Zinman B, Wanner C, Lachin JM, Fitchett D, Bluhmki E, Hantel S, Mattheus M, Devins T, Johansen OE, Woerle HJ, Broedl UC, Inzucchi SE, EMPA-REG OUTCOME Investigators. Empagliflozin, cardiovascular outcomes, and mortality in type 2 diabetes. $\mathrm{N}$ Engl J Med. 2015;373:2117-28.

3. Neal B, Perkovic V, Matthews DR, Mahaffey KW, Fulcher G, Meininger G, Erondu N, Desai M, Shaw W, Vercruysse F, Yee J, Deng H, de Zeeuw D, CANVAS-R Trial Collaborative Group. Rationale, design and baseline characteristics of the
CANagliflozin cardioVascular Assessment Study-Renal (CANVAS-R): a randomized, placebo-controlled trial. Diabetes Obes Metab. 2017;19:387-93.

4. Wiviott SD, Raz I, Bonaca MP, Mosenzon O, Kato ET, Cahn A, Silverman MG, Bansilal S, Bhatt DL, Leiter LA, McGuire DK, Wilding JP, Gause-Nilsson IA, Langkilde AM, Johansson PA, Sabatine MS. The design and rationale for the Dapagliflozin Effect on Cardiovascular Events (DECLARE)-TIMI 58 Trial. Am Heart J. 2018;200:83-9.

5. Kosiborod M, Cavender MA, Fu AZ, Wilding JP, Khunti K, Holl RW, Norhammar A, Birkeland KI, Jørgensen ME, Thuresson M, Arya N, Bodegård J, Hammar N, Fenici P, CVD-REAL Investigators and Study Group*. Lower risk of heart failure and death in patients initiated on sodium-glucose cotransporter-2 inhibitors versus other glucose-lowering drugs: the CVD-REAL Study (Comparative Effectiveness of Cardiovascular Outcomes in New Users of Sodium-Glucose Cotransporter-2 Inhibitors). Circulation. 2017;136:249-59.

6. Ganbaatar B, Fukuda D, Shinohara M, Yagi S, Kusunose K, Yamada H, Soeki T, Hirata KI, Sata M. Empagliflozin ameliorates endothelial dysfunction and suppresses atherogenesis in diabetic apolipoprotein E-deficient mice. Eur J Pharmacol. 2020;875:173040.

7. Lee DM, Battson ML, Jarrell DK, Hou S, Ecton KE, Weir TL, Gentile CL. SGLT2 inhibition via dapagliflozin improves generalized vascular dysfunction and alters the gut microbiota in type 2 diabetic mice. Cardiovasc Diabetol. 2018;17:62.

8. Gaspari T, Spizzo I, Liu H, Hu Y, Simpson RW, Widdop RE, Dear AE. Dapagliflozin attenuates human vascular endothelial cell activation and induces vasorelaxation: a potential mechanism for inhibition of atherogenesis. Diab Vasc Dis Res. 2018;15:64-73.

9. Correale M, Totaro A, Greco CA, Musaico F, De Rosa F, Ferraretti A, Ieva R, Di Biase M, Brunetti ND. Tissue Doppler Time Intervals predict the occurrence of re-hospitalization in chronic heart failure: data from the Daunia Heart Failure Registry. Echocardiography. 2012;29:906-13.

10. Correale M, Brunetti ND, Totaro A, Montrone D, Russo AR, Fanigliulo AM, Ieva R, Di Biase M. Statin therapy blunts inflammatory activation and improves prognosis and left ventricular performance assessed by tissue Doppler imaging in subjects with chronic ischemic heart failure: results from the Daunia Heart Failure Registry. Clinics. 2011;66:777-84.

11. Correale M, Totaro A, Ferraretti A, Musaico F, Passero T, De Rosa F, Abruzzese S, Ieva R, Di Biase M, Brunetti ND. Additional Prognostic Value of EAS index in predicting the occurrence of rehospitalizations in chronic heart failure: data from the Daunia Heart Failure Registry. Eur J Clin Invest. 2015;45:1098-105.

12. Seferović PM, Petrie MC, Filippatos GS, Anker SD, Rosano G, Bauersachs J, Paulus WJ, Komajda M, Cosentino F, de Boer RA, Farmakis D, Doehner W, Lambrinou E, Lopatin Y, Piepoli MF, Theodorakis MJ, Wiggers H, Lekakis J, Mebazaa A, Mamas MA, Tschöpe C, Hoes AW, Seferović JP, Logue J, McDonagh T, Riley JP, Milinković I, Polovina M, van Veldhuisen DJ, Lainscak M, Maggioni AP, Ruschitzka F, McMurray JJV. Type 2 diabetes mellitus and heart failure: a position statement from the Heart Failure Association of the European Society of Cardiology. Eur J Heart Fail. 2018;20:853-72.

13. Davies MJ, D’Alessio DA, Fradkin J, Kernan WN, Mathieu C, Mingrone G, Rossing P, Tsapas A, Wexler DJ, Buse JB, Management of hyperglycaemia in type 2 diabetes, 2018. A consensus 
report by the American Diabetes Association (ADA) and the European Association for the Study of Diabetes (EASD). Diabetologia. 2018;2018(61):2461-98.

14. Cosentino F, Grant PJ, Aboyans V, Bailey CJ, Ceriello A, Delgado V, Federici M, Filippatos G, Grobbee DE, Hansen TB, Huikuri HV, Johansson I, Jüni P, Lettino M, Marx N, Mellbin LG, Östgren CJ, Rocca B, Roffi M, Sattar N, Seferović PM, Sousa-Uva M, Valensi P, Wheeler DC, ESC Scientific Document Group. 2019 ESC Guidelines on diabetes, pre-diabetes, and cardiovascular diseases developed in collaboration with the EASD. Eur Heart J. 2020;41:255-323.

15. Corretti MC, Anderson TJ, Benjamin EJ, Celermajer D, Charbonneau F, Creager MA, Deanfield J, Drexler H, Gerhard-Herman M, Herrington D, Vallance P, Vita J, Vogel R, International Brachial Artery Reactivity Task Force. Guidelines for the ultrasound assessment of endothelial-dependent flow-mediated vasodilation of the brachial artery: a report of the International Brachial Artery Reactivity Task Force. J Am Coll Cardiol. 2002;39:257-65.

16. Correale M, Leopizzi A, Mallardi A, Ranieri A, Suriano MP, D'Alessandro D, Tricarico L, Mazzeo P, Tucci S, Pastore G, Maulucci G, Di Biase M, Brunetti ND. Switch to direct anticoagulants and improved endothelial function in patients with chronic heart failure and atrial fibrillation. Thromb Res. 2020;195:16-20.

17. Maulucci G, Cipriani F, Russo D, Casavecchia G, Di Staso C, Di Martino L, Ruggiero A, Di Biase M, Brunetti ND. Improved endothelial function after short term therapy with evolocumab. $\mathrm{J}$ Clin Lipidol. 2018;12:669-73.

18. Correale M, Paolillo S, Mercurio V, Limongelli G, Barillà F, Ruocco G, Palazzuoli A, Scrutinio D, Lagioia R, Lombardi C, Lupi L, Magrì D, Masarone D, Pacileo G, Scicchitano P, Matteo Ciccone M, Parati G, Tocchetti CG, Nodari S. Comorbidities in chronic heart failure: an update from Italian Society of Cardiology (SIC) Working Group on Heart Failure. Eur J Intern Med. 2020;71:23-31.

19. Correale M, Brunetti ND, Totaro A, Montrone D, Russo AR, Fanigliulo AM, Ieva R, Di Biase M. Statin therapy blunts inflammatory activation and improves prognosis and left ventricular performance assessed by Tissue Doppler Imaging in subjects with chronic ischemic heart failure: results from the Daunia Heart Failure Registry. Clinics. 2011;66:777-84.

20. Tsutsui H, Kinugawa S, Matsushima S. Oxidative stress and heart failure. Am J Physiol Heart Circ Physiol. 2011;301:H2181-90.

21. Osorio H, Coronel I, Arellano A, Pacheco U, Bautista R, Franco M, Escalante B. Sodium-glucose cotransporter inhibition prevents oxidative stress in the kidney of diabetic rats. Oxid Med Cell Longev. 2012;2012:542042.

22. Lin B, Koibuchi N, Hasegawa Y, Sueta D, Toyama K, Uekawa K, Ma M, Naka-gawa T, Kusaka H, Kim-Mitsuyama S. Glycemic control with empagliflozin a novel selective SGLT2 inhibitor, ameliorates cardiovascular injury and cognitive dysfunction in obese and type 2 diabetic mice. Cardiovasc Diabetol. 2014; $13: 148$

23. Tahara A, Kurosaki E, Yokono M, Yamajuku D, Kihara R, Hayashizaki Y, Takasu T, Imamura M, Li Q, Tomiyama H, Kobayashi Y, Noda A, Sasamata M, Shibasaki M. Effects of SGLT2 selective inhibitor ipraglifozin on hyperglycemia, hyperlipidemia, hepatic steatosis, oxidative stress, inflammation, and obesity in type 2 diabetic mice. Eur J Pharmacol. 2013;715:246-55.

24. Oelze M, Kroller-Schon S, Welschof P, Jansen T, Hausding M, Mikhed Y, et al. The sodium-glucose co-transporter 2 inhibitor empagliflozin improves diabetes-induced vascular dysfunction in the streptozotocin diabetes rat model by interfering with oxidative stress and glucotoxicity. PLoS ONE. 2014;9:e112394.

25. Salim HM, Fukuda D, Yagi S, Soeki T, Shimabukuro M, Sata M. Glycemic control with ipragliflozin, a novel selective SGLT2 inhibitor, ameliorated endothelial dysfunction in streptozotocininduced diabetic mouse. Front Cardiovasc Med. 2016;3:43.

26. Juni RP, Kuster DWD, Goebel M, Helmes M, Musters RJP, van der Velden J, Koolwijk P, Paulus WJ, van Hinsbergh VWM. Cardiac microvascular endothelial enhancement of cardiomyocyte function is impaired by inflammation and restored by empagliflozin. JACC Basic Transl Sci. 2019;4:575-91.

27. Shigiyama F, Kumashiro N, Miyagi M, Ikehara K, Kanda E, Uchino H, Hirose T. Effectiveness of dapagliflozin on vascular endothelial function and glycemic control in patients with earlystage type 2 diabetes mellitus: DEFENCE study. Cardiovasc Diabetol. 2017;16:84.

28. Solini A, Giannini L, Seghieri M, Vitolo E, Taddei S, Ghiadoni L. Bruno RM Dapagliflozin acutely improves endothelial dysfunction, reduces aortic stiffness and renal resistive index in type 2 diabetic patients: a pilot study. Cardiovasc Diabetol. 2017;16:138.

29. Tanaka, et al. Rationale and design of a multicenter placebocontrolled double-blind randomized trial to evaluate the effect of empagliflozin on endothelial function: the EMBLEM trial. Cardiovasc Diabetol. 2017;16:48.

30. Tanaka A, Shimabukuro M, Machii N, Teragawa H, Okada Y, Shima KR, Takamura T, Taguchi I, Hisauchi I, Toyoda S, Matsuzawa Y, Tomiyama H, Yamaoka-Tojo M, Ueda S, Higashi Y, Node K. Secondary analyses to assess the profound effects of empagliflozin on endothelial function in patients with type 2 diabetes and established cardiovascular diseases: the placebocontrolled double-blind randomized effect of empagliflozin on endothelial function in cardiovascular high risk diabetes mellitus: Multi-center placebo-controlled double-blind randomized trial. J Diabetes Investig. 2020. https://doi.org/10.1111/jdi.13289.

31. Tanaka A, Shimabukuro M, Okada Y, Sugimoto K, Kurozumi A, Torimoto K, Hirai H, Node K, PROCEED trial investigators. Rationale and design of an investigator-initiated, multicenter, prospective open-label, randomized trial to evaluate the effect of ipragliflozin on endothelial dysfunction in type 2 diabetes and chronic kidney disease: the PROCEED trial. Cardiovasc Diabetol. 2020;19:85.

32. Breder I, Cunha Breder J, Bonilha I, Munhoz DB, Medorima STK, Oliveira DC, do Carmo HR, Moreira C, Kontush A, Zimetti F, Zanotti I, Carvalho LSF, Nadruz W, Muscelli E, Quinaglia T, Sposito AC, EXCEED-BHS3 Trial Investigator. Rationale and design of the expanded combination of evolocumab plus empagliflozin in diabetes: EXCEED-BHS3 trial. Ther Adv Chronic Dis. 2020;11:2040622320959248.

33. Sposito AC, Breder I, Soares AAS, Kimura-Medorima ST, Munhoz DB, Cintra RMR, Bonilha I, Oliveira DC, Breder JC, Cavalcante P, Moreira C, Moura FA, de Lima-Junior JC, do Carmo HRP, Barreto J, Nadruz W, Carvalho LSF, Quinaglia T, ADDENDA-BHS2 trial investigators. Dapagliflozin effect on endothelial dysfunction in diabetic patients with atherosclerotic disease: a randomized active-controlled trial. Cardiovasc Diabetol. 2021;20:74

34. Lee HC, Shiou YL, Jhuo SJ, Chang CY, Liu PL, Jhuang WJ, Dai ZK, Chen WY, Chen YF, Lee AS. The sodium-glucose cotransporter 2 inhibitor empagliflozin attenuates cardiac fibrosis and improves ventricular hemodynamics in hypertensive heart failure rats. Cardiovasc Diabetol. 2019;18:45. 
35. Loutradis C, Papadopoulou E, Theodorakopoulou M, Karagiannis A, Sarafidis P. The effect of SGLT-2 inhibitors on blood pressure: a pleiotropic action favoring cardio- and nephroprotection. Future Med Chem. 2019;11:1285-303.

36. Filippatos TD, Liontos A, Papakitsou I, Elisaf MS. SGLT2 inhibitors and cardioprotection: a matter of debate and multiple hypotheses. Postgrad Med. 2019;131:82-8.

37. Irace C, Cutruzzolà A, Parise M, Fiorentino R, Frazzetto M, Gnasso C, Casciaro F, Gnasso A. Effect of empagliflozin on brachial artery shear stress and endothelial function in subjects with type 2 diabetes: results from an exploratory study. Diab Vasc Dis Res. 2020;17:1479164119883540.

38. Irace C, Casciaro F, Scavelli FB, et al. Empagliflozin influences blood viscosity and wall shear stress in subjects with type 2 diabetes mellitus compared with incretin-based therapy. Cardiovasc Diabetol. 2018;17:52.
39. Li H, Shin SE, Seo MS, An JR, Choi IW, Jung WK, Firth AL, Lee DS, Yim MJ, Choi G, Lee JM, Na SH, Park WS. The anti-diabetic drug dapagliflozin induces vasodilation via activation of PKG and Kv channels. Life Sci. 2018;197:46-55.

40 Sano M. Sodium glucose cotransporter (SGLT)-2 inhibitors alleviate the renal stress responsible for sympathetic activation. Ther Adv Cardiovasc Dis. 2020;14:1753944720939383.

41. Scheen AJ. Effect of SGLT2 inhibitors on the sympathetic nervous system and blood pressure. Curr Cardiol Rep. 2019;21:70.

Publisher's Note Springer Nature remains neutral with regard to jurisdictional claims in published maps and institutional affiliations. 